\title{
Interactivity in Virtual Learning Groups: Theories, Strategies, and the State of Literature
}

\author{
Jessica Cara Ng
}

\begin{abstract}
The existence and survival of virtual learning groups (VLGs) depends upon the satisfaction, learning, and retention of their students. This paper reviews literature that offers strategies for effective teaching and learning in VLGs, focusing on major theoretical perspectives about interactivity. It identifies gaps, shortfalls, and conflicts in extant research on virtual education and suggests next steps scholars should take to make literature and research in this area more robust.
\end{abstract}

Index Terms - Education technology, interactivity, virtual learning, virtual learning groups.

\section{INTRODUCTION}

Communication technology's effects on virtual groups are a topic of longstanding concern. Despite decades of research there appears little consensus on how to shape the development of virtual learning groups (VLGs) to encourage participation and increase their effectiveness. This paper will review literature that offers strategies for effective teaching and learning in virtual learning groups, focusing on major theoretical perspectives about interactivity in virtual communication and the implications each perspective offers for shaping virtual groups' interactions and effectiveness. The paper studies the strategies and frameworks/theories used to enhance learning in virtual groups and identifies conflicts in existing literature. It concludes by proposing ways that can help increase the likelihood of creating a learning environment that promotes deep and meaningful learning, and is satisfying to students.

\section{BACKGROUND AND THEORETICAL THEMES}

Online learning holds great appeal to a large number of people all over the world due to its flexibility, ease of access, and convenience. Allen and Seaman reported that over 6.7 million college students were taking at least one online course during fall 2012, representing 32\% of all higher education students in United States [1].

Although some forms of virtual learning, such as massive open online courses (MOOCs) are highly glorified and immensely popular in this new technological age, critics are skeptical of such enthusiasm, arguing that the benefits are largely theoretical [2]. Empirical research has shown mixed

Manuscript received June 11, 2015; revised September 23, 2015. This work was supported in part by Nanyang Technological University.

J. C. $\mathrm{Ng}$ is with the Wee Kim Wee School of Communication and Information, Nanyang Technological University, Singapore (e-mail: sng036@e.ntu.edu.sg). evidence of the effectiveness of such forms of virtual learning. Some studies have shown that students report feeling isolated and alone while taking online courses [3]-[5], which eventually results in lower student satisfaction in online courses and lower persistence levels. The rates of students who fail to complete their online courses range from $10 \%$ to $75 \%$ [6]-[8].

This poses a huge threat to online learning courses: If students do not stay on and complete a course, or if they feel dissatisfied while taking the online course, it will adversely affect their learning, or, there will be no learning at all. Persistence and satisfaction form the foundation of learning [9], without which, learning may not occur, hence, the importance of looking at students' persistence and satisfaction.

Online courses facilitate learning through VLGs, which consist of students who learn together primarily via technology and computer-mediated communication (CMC) while remaining, for the most part, geographically dispersed. They are aptly defined as groups in which "students discuss learning materials or cooperate in problem-solving by means of CMC" [10].

To proceed, we need to understand the root causes of why students do not persist in VLGs and what causes them to drop out or not participate at all. Previous studies have highlighted various factors, which include family pressures, problems with technology, and finances [11]-[13]. These factors can be classified as external factors (factors which the participant exercise little or no control over). Also, there are internal factors such as self-motivation and self-determination (factors which the participant can exercise control over). Lastly, other factors highlighted by researchers include poorly designed courses, lack of interactivity, feelings of isolation and loneliness, and lack of instructor presence [8], [14]-[16]. These factors are labeled as communication factors (factors affected by communication processes in virtual learning groups).

Although some of the factors listed above are beyond the control of course designers, researchers, and administrators (e.g., family pressure, time constraints, self-determination), some of them (communication factors such as interactivity and presence) are at the heart of online course design, which course designers can control for in VLGs. Previous studies have reached the consensus that some form of interaction is advantageous to learning in an online environment. This paper reviews the literature on interactions in VLGs and surveys the various factors and deliberate strategies that scholars have suggested to help students learn better and more effectively in virtual learning groups. 


\section{LITERATURE REVIEW}

\section{A. Interactivity}

Interactivity is defined as the degree to which a communication technology can create a mediated environment in which participants can communicate both synchronously and asynchronously, and participate in reciprocal message exchanges [17]. According to Rafaeli, interactivity, or third order dependency among communicators' messages is any third (or later) message is related to previous exchanges made between users [18]. This definition of interactivity means that with regard to human users, interactivity refers to their ability to perceive their virtual interactions (online) as interpersonal communication (offline) and consequently increase their awareness of telepresence, thereby blurring the line between offline and online communication, or interactions [17].

Using this definition, we review literature on interactivity and various theories which have highlighted the importance of interactions in virtual learning, followed by empirical studies which support or contradict the theories.

\section{B. The Seven Principles for Good Practice in Education}

Not a theory per se, four of the seven principles ${ }^{1}$ delineated by Chickering and Gamson on good practices in undergraduate education form a good basis on which we can look at learning in VLGs and further frame the theories reviewed in this literature [19]. They include:

1) Encourage contacts between students and faculty

2) Develop reciprocity and cooperation among students

3) Use active learning techniques (that is, students are to be participants in knowledge construction instead of passive recipients of information)

4) Give prompt feedback

Although these principles were not designed with virtual learning in mind, we will notice that their arguments still stand in today's world of virtual learning. We will revisit these principles after reviewing literature and surveying the various factors and deliberating strategies that researchers have suggested to help VLGs become more effective.

\section{Social Constructivist Theory}

From the social constructivist viewpoint, learning occurs when students' perspectives and experiences are brought into collaborative work where there is an integration of ideas [20], and when students interact and explain their thinking to one another, they experience deeper learning [21]. As posited by Vygotsky, cognitive functions, or learning, are products of social interactions [22]. Learning is not simply the assimilation and accommodation of new knowledge by learners, but is the process by which learners are integrated into a knowledge community.

As can be deduced from the social constructivist's viewpoint, learning occurs when knowledge is actively constructed. This greatly contrasts the traditional classroom teaching model where a teacher disseminates knowledge and a student simply receives information with no stake in

\footnotetext{
${ }^{1}$ The last three principles by Chickering and Gamson (1987) are not of relevance to this paper:: 5. Emphasise time on task, 6. Communicate high expectations, 7. Respect diverse talent and ways of learning
}

knowledge construction. According to Hall, for knowledge to be constructed, individuals need to converse and interact with one another [23]. In other words, they need to engage in active, as opposed to, passive learning.

Bringing these arguments into VLGs, we can see that there are affordances which allow students to interact with one another usually through asynchronous, threaded forums or discussion boards. Based on the social constructivist theory, interactions through collaborations and knowledge construction should predict significant levels of learning in students [24]. In one study, it was found that student-to-student interactions via the ability to share their learning experiences with one another and their ability to communicate with others in the course, increased their sense of community and encouraged them to work in teams. These interactions also contribute significantly to students' learning and satisfaction [24]. This study did not, however, examine the frequency of the interactions nor the depth of interactions between students which led to this significant finding. We cannot be sure of what exactly (depth, or types or other factors) constitutes and promotes learning and satisfaction in student-to-student interactions in VLGs because previous studies have analysed such attitudes via questionnaires or surveys only.

Several approaches to designing virtual learning groups can be derived from existing precedents and theoretical suggestions from the social constructivist perspective, however. One would be for course instructors to design collaborative work or tasks in manners which would elicit the sharing of students' experiences and to use their experiences in the construction of meaning and knowledge [20]-[22].

A second, and complementary strategy would be to ensure there are easy-to-use and easy-to-access channels for participants in VLGs to interact, communicate and/or collaborate with one another - either synchronously or asynchronously - as to allow participants the opportunity to share and work together. Very few empirical studies have been found to study if the nature of communication, whether synchronous or asynchronous, has a significant effect on student's learning and satisfaction in virtual groups. A meta-analytic study wasdesigned by a group of researchers to test if the nature of feedback between student and instructor may impact the level of learning. They defined a synchronous system as a condition where "comments, question, or feedback were simultaneous" and it "involves a "live" instructor with whom the students may directly communicate with". Conversely, they defined an asynchronous system as one in which "the student cannot directly communicate with an instructor" [25]. They reported that:

There does not seem to be support for the implementation of synchronous interactive technologies or classrooms to increase performance. Performance did not differ as a result of the use of synchronous interactive technologies [25] .

They defined performance as the ability to master content and skills. Their finding seems to suggest that asynchronous communication is as good as synchronous communication in VLGs. However, we need to bear in mind that they were only studying academic performance and not students' satisfaction and retention, which are the focus of this paper.

Furthering this claim on the relative substitutability of 
synchronous and asynchronous interaction, Anderson claimed that:

I have been informally polling students about the relative advantage and disadvantage of various forms of mediated and face-to-face, synchronous and asynchronous, educational activities. From these polls, I conclude that there is a wide range of need and preference for different combinations of paced and un-paced, synchronous and asynchronous activity, and also a strong desire for variety and exposure to different modes and modularities of educational provision and activity [26].

What this tells us, at best, is that a mix of synchronous and asynchronous communication is required in an effective VLG It does not, however, answer the question of whether the two different forms of communication or interaction have significantly different effects on students' learning and satisfaction in VLGs. This area of nature of communication in virtual learning remains to be tested and studied.

Bernard, Abrami, Borokhovski, Wade, Tamim, Surkes and Bethel, through their meta-analysis on the types of interactions (student-student, student-instructor, student-content) and their effects on students' achievement, attitudes and course completion rates, suggest that it may not be about the mode of communication (whether synchronous or asynchronous or mix) that is affecting students' achievement, attitudes and persistence in VLGs, but the quality and strength of interactions within each mode of interaction [27]. The authors noted, however, that they did not have sufficient evidence and data on the specific interaction treatments and types of interactions that participants engaged in to make a conclusion on this front. Hence, further strengthening the argument of the importance of deciphering and pinpointing specificities (types, frequencies, depth) of interactions that take place in VLGs.

This conflict in existing literature on the mode of communication in VLGs and learning begs an answer. The question of whether the two different forms of interactions have significantly different effects on students' learning and satisfaction in virtual learning groups remain to be answered. On top of that, Bernard et al.'s study adds another layer to this argument: do the modes of interaction matter or do their quality, frequency and type matter more? This area of nature of communication in virtual learning remains to be tested and studied.

\section{Social Integration Theory}

The social integration theory emphasises the importance of a sense of belonging in students to their learning environments through active participation in communities. As explained by Tinto, persistence in college, is not only attributed to individual characters, but the outcome of a longitudinal process of interactions between individuals and their peers, faculty, and administration of their school [9], [28], [29]. These interactions may take the form of formal (academic performance) and informal (faculty/staff interactions) academic systems and formal (extracurricular activities) and informal (peer-group) social systems [30]. In order for students to persist in an academic course, it is important for them to be engaged or involved in communities (e.g. student council, co-curricular activities, interest groups, sports groups, subject groups). According to the tenets of the social integration theory, involvement in such communities will enhance a student's sense of belonging through communication and interaction with others in the same environment.

Liu, Gomez, Khan, and Yen examined students' level of persistence and their sense of a community within a VLG. In a case study of 28 faculty members and 20 online MBA students, the authors noted a relationship between students' sense of community and lowered feelings of isolation as well as reductions in likelihood that they will drop out of their online course [31]. In other words, when students feel a sense of community in their online course environments, likelihood of persistence is strengthened [13], [31], [32].

Drawing upon the social integration theory, several strategies may be suggested to improve the effectiveness of VLGs. First, VLGs should be designed to allow for information exchange, discussions, and interactions between peers and instructors. For example, virtual features which facilitate communal behaviour such as forums, discussion boards, and emails should be present and easily accessible in VLGs to allow for communication and connection with others.

Second, apart from installing features which allow communal behaviour, virtual learning groups should encourage the formation of formal (e.g. class groups, small in-class groups for collaborative work) or informal (e.g. location-based communities to allow for informal meet-ups, college-based communities, interest-based communities) communities to further enhance a student's sense of community.

Third, drawing upon social identification theory, to increase commitment and retention in such smaller communities within VLGs and subsequently the VLGs as a whole, group saliency should be designed into communities in VLGs. Farzan, Dabbish, Kraut, and Postmesfound that interpersonal attraction and group saliency may increase group members' commitment and increase retention rates in virtual communities. They examined the notion of commitment in online communities by emphasising on interpersonal relationships between individuals and the saliency of a community as an entity [33]. This study draws on the social identification theory - when social identification is great,then group attraction is great and members value being a part of the group and desire to be valued members[34]. Farzan et al.'s study reflected on these social identification principles by arguing that in all communities, it appears that the encouragement of the formation of shared identities help to increase commitment of members to an online community [33]. This study, although did not deal with interactions specifically, adds another layer to the notion of communities expounded in this section - if done correctly, an increase in group saliency and group identification would enhance commitment and retention rates, which would then fuel more interactions and sense of belonging to the communities and VLGs.

\section{E. Interaction Equivalency Theorem}

Anderson, in the interaction equivalency theorem, suggests that meaningful learning can occur when at least one of these 
three forms of interaction is present at a high level: student-student, student-instructor, and student-content. This theorem implies that an online course designer can substitute one type of interaction for one of the others with little loss in educational effectiveness [26].

Student-student. Student interactions, according to Miyazoe and Anderson, meant interactions with other course members (e.g., collaborative or cooperative learning) [35]. In line with the social constructivists, peer-to-peer interactions allow for the investigation and development of multiple perspectives on an issue, which help students to learn [36].

Prior research has examined the importance of student-to-student-interactions in online courses. Walker and Kelly set out to answer the question of what contributes to student satisfaction in online learning by surveying graduate and undergraduate students at the end of their online courses in the University of Oklahoma. They found that more than half of the respondents claimed that "they enjoy sharing their work and getting comments from other students in the course" and when asked for the worst features of the VLG, "quality of interactions" was a frequently cited feature. The authors noted that this had to do with the students feeling isolated as they were not able to interact with their peers, citing the typical comment, "I wish there was more interaction among students" [37]. They reported that one of the disadvantages most frequently cited by students with respect to VLGs is that there is no opportunity for interaction with classmates. Although this study was done on online learning in general and not on VLGs specifically, the finding can be extrapolated to highlight the importance of affording for interactions within VLGs. The finding also lends support to Anderson's claim that student-student interactions are an important arm in creating meaningful learning in virtual groups [26].

Also susceptible to similar criticisms as Sher'sstudy [24] as reviewed in an earlier section, Walker and Kelly's [37] study failed to reveal exactly what types, frequency, and depth of interactions participants crave for and the meaning of "quality of interactions" is, at best, dubious.

Comparing this perspective of peer interactions with that of the social constructivist's, the interaction equivalency theorem does not seem to emphasise learning through the sharing of one's own experiences and the integration of student-to-student ideas and experiences to construct knowledge and meaning. Instead, its emphasis is on the ability for students to be able to converse, or perceive the presence of one another. In other words, the social constructivist presents us with the kind of interactions that will lead to learning, albeit vague in terms of specificities, while the interaction equivalency theorem simply states the importance of peer-to-peer activity, whichever form it may take. An important question we want to ask here is: do the types of interactions matter in terms of raising students' learning, satisfaction, and retention in VLGs, or is higher frequency, or more communication sufficient? Literature thus far is still mixed in terms of the specificities of interactions required, although, is has established, in general terms, that interactivity is important in VLGS. This point has also been brought up by Bernard et al. - they highlighted the importance to distinct actual behaviors which constitute the three types of interactions so they may be observed or measured, however they are seldom described and reported in research papers in sufficient depth and precision to allow for a systematic review of education literature [27].

Meriting note in this section, however, is that student-to-student interactions are generally agreed amongst scholars to positively affect learning, satisfaction and retention rates in virtual learning groups, they remain to be studied in greater detail. The measures and definitions used by the researchers in this literature should be fine-tuned and tested in greater detail and depth in order to single out the intricacies of student-to-student interactions that best enhance learning in VLGs. As mentioned by Bernard et al., while conducting a meta-analysis on interactions and learning in virtual education, they were unable to find measures to code for activities as well as quality and quantity of interactions which would make it possible for them to connect them with measures of achievement, attitudes and persistence [27]. Hence, forming a gap in their findings. This highlights the importance of such data in order to advance the virtual education literature.

Student-instructor. Student-instructor interactions refer to the ability for students and teachers to interact, either via synchronous or asynchronous communication platforms using text, audio, and/or video [36]. They can include emails, forums, or feedback from instructors to students with regards to their work or progress in a course.

Thurmond, Wambach, Connors, and Frey developed a questionnaire to find out how a student's level of satisfaction in a VLG differs from a traditional classroom setting. To capture student's evaluation of web-based learning versus that of a traditional, face-to-face classroom, they asked this question in relation to student-instructor interaction: "Compared to a similar course that relied primarily on face-to-face discussions, because of the way this course uses electronic communications (e-mails, computer conferences, chat groups, online discussions), how likely are you to feel like you know the instructor?". They reported that students who perceived that they knew the instructor through the VLG via CMC tended to believe that they were better assessed. Those who responded most positively about knowing the instructor reported actively participating more in online discussions [14]. The findings seem to indicate that interactions, or the perceived interactions with, and presence of an instructor, foster a belief in students that they were being adequately assessed which increased satisfaction and encouraged participation in virtual discussions. These findings support the social integration theory's argument on the importance of having a sense of community in VLGs.

In another study exploring interaction equivalency theorem, Rhode wanted to find out what forms of interaction learners value most in VLGs [38]. Participants were asked to rank course elements of highest importance to them. It was reported that the most important aspects of a VLG to participants are interactions with the instructor and quality course content. Although the depth and frequencies of such interactions were, again, not specified, this study gave us insights as to the kinds of student-instructor interactions students in VLGs hope to have. It can, also, be gleaned from these empirical studies that student-instructor interactions do have a part to play in enhancing learning in VLGs. 
A practical deduction from empirical studies reviewed thus far, is that feedback may be a type of student-instructor interaction that has astounding effects on learning.

To look at feedback in VLGs in more detail, Espasa and Menesesreported that there is a statistically significant relationship between instructor feedback to students and the results of students' grades [39]. Another study by Soon, Sook, Jung, and Im obtained questionnaire responses from sixty students on their satisfaction at the end of online course. One area that received the most number of negative responses from the students included insufficient feedback from professors regarding reports and questions [40]. Implications of these empirical studies suggest that feedback from instructors may form an important arm in increasing students' learning, satisfaction and retention.

A shortfall of previous research which looked at the student-instructor interactions, is the lack of a clear indication of the types of student-instructor interactions that may be most practical and effective to be implemented in VLGs. The literature suggests that such interactions contribute to better retention rates, better student grades, and higher student satisfaction, but such interactions were vaguely described and tested. Similar to student-to-student interactions, more detailed studies need to be conducted to find out the exact types, kinds, depth, and frequencies of such interactions which best contribute to students' learning and satisfaction in VLGs.

Student-content. The last component in this theorem is that of student-content interaction. Building upon the argument put forth by Berners-Lee, who describes the semantic Web as an environment in which content is formulated, stored, searched and computed automatically through technology, this capacity allows for the development of useful teacher and learner agents, which encourage the migration to content-based forms of interaction instead of human-to-human interactions [41]. This arm of the interaction equivalency theorem (student-content interaction), however, is not the focus of this paper. Based on the earlier definition by Kiousis of interactivity used for this paper [17], the focus of this paper is on the human-to-human element of interactions, which allows for reciprocity of communication.

\section{DISCUSSION}

The table below (Table I), summarises how the various theories reviewed fall into the principles as posited by Chickering and Gamson [19]:

As evident from Table I, there is no clear demarcation of which one principle or theory will yield the most effective results in improving the effectiveness of VLGs. Although vastly different theories which originated from different time periods and to answer different questions, the theories come together quite cohesively under the seven principles framework. This indicates that there is consistency in the virtual education literature - scholars agree on the importance of general principles such as active knowledge construction, interactions and feedback in virtual education. The review, however, also revealed the lack of depth and precision in extant research. Although scholars confirmed the dominant theories, they failed to illustrate the finer details of interactions, which they speak of. For example, many scholars pointed out that student-to-instructor interactions are instrumental in the learning and satisfaction of students in VLGs. They did not provide more detailed information on the types of interactions students are looking for, the frequency of interactions, or the depths of interactions students endeavour to have when engaged in VLGs. In a similar vein, such important details were also left out in student-to-student interactions research. As previously emphasised, such specificities are necessary to advance virtual education research.

TABLE I: LEARNING THEORIES AND THE 7 PRINCIPLES

Principles for Good Practice in Education

\begin{tabular}{lllll}
\hline \hline & $\begin{array}{l}\text { 1. Student-faculty } \\
\text { interactions }\end{array}$ & $\begin{array}{l}\text { 2. Student-student } \\
\text { interactions }\end{array}$ & 3. Construction of knowledge & 4. Giving prompt feedback \\
\hline \multirow{3}{*}{$\begin{array}{l}\text { Theories/Frameworks } \\
\text { reviewed }\end{array}$} & $\begin{array}{l}\text { Interaction equivalency } \\
\text { theorem }\end{array}$ & $\begin{array}{l}\text { Interaction equivalency } \\
\text { theorem }\end{array}$ & $\begin{array}{l}\text { Interaction equivalency } \\
\text { theorem }\end{array}$ \\
\cline { 2 - 5 } & Social integration theory & Social integration theory & Social integration theory & Social integration theory \\
\cline { 2 - 5 } & & Social constructivist theory & Social constructivist theory & \\
\hline \hline
\end{tabular}

Another important gap has been identified while reviewing literature on interactions and virtual learning. While scholars argue for the importance of interactions, they seem to group all kinds of communication under the umbrella of interactions without deciphering if any one mode of communication may supersede another in achieving the learning outcomes they are after. VLGs are set in the virtual world, in which, most communication is computer-mediated. CMC can be synchronous or asynchronous. Anderson,in his interaction equivalency theorem, posits that interaction, whether synchronous or asynchronous, can lead to positive learning outcomes, without providing empirical evidence that both types of communication lead to similar levels of effectiveness in learning, satisfaction, or persistence in students [26]. Bernard et al. brought out a contrasting point, reportingthat student achievement, satisfaction and persistence in virtual learning groups have more to do with the quality and depth of interactions rather than the types [27]. Hence, we ask: Does synchronous and asynchronous CMC yield the same learning outcomes in virtual learning groups? This is an important question to answer as it will provide VLGs designers and instructors with valuable feedback as to how best to allocate their resources. Also, do the mode (synchronous, asynchronous or mix) not matter as long as they are of a certain depth, frequency and quality? These are two important questions under the umbrella of communication modes in 
VLGs that need to be answered.

Lastly, according to the interaction equivalency theorem, one is able to effectively substitute one form of interaction (student-student, student-instructor, student-content) for another. In Anderson's words:

"Deep and meaningful formal learning is supported as long as one of the three forms of interaction is at a high level. The other two may be offered at minimal levels, or even eliminated, without degrading the educational experience" [26].

This literature has reviewed empirical studies which highlight the importance of student-student and student-instructor interactions. No empirical study, however, seems to have studied the substitution effect as mentioned by Anderson. What previous research has done is to separately test each type of interaction but no comparative study has been done on the substitutability of student-student and student-faculty interactions in VLGs. Hence, till now, we are unable to make the claim that student-student or student-instructor interactions will yield the same, or similar levels of satisfaction, and/or persistence, or, in other words, substituting one type of interaction for the other will not significantly affect students' learning, satisfaction or retention in VLGs. Hence, the equivalence in the interaction equivalency theorem remains to be tested.

\section{LIMITATIONS IN THEORIES REVIEWED}

The present research reviewed three theoretical approaches to highlight the importance of interactions in learning groups and suggested general types of interactions to increase the effectiveness of virtual learning groups. The interactions suggested by literature are as follows:

1) Active construction of knowledge through sharing of ideas and experiences (social constructivism)

2) Collaboration (social constructivism, interaction equivalency, social integration)

3) Communities which build a sense of identity in students (social integration)

4) Instructor feedback (interaction equivalency, social integration)

Although each strategy has some theoretical grounding, it has been established through the previous sections that they lack details and precision when it comes to the exact types, depth, frequency, and nature of communication (asynchronous or synchronous) which are required to produce the best results in student learning in VLGs. Also, the interaction equivalency points out the importance of any of type of interaction (student-student, student-instructor, student-content) in virtual learning groups, empirical data has yet to provide solid grounding to their ability to substitute one another in any one virtual learning scenario. Thus, it remains unclear how interactions should be incorporated and designed into VLGs. Only minimal guidance is available with which to consider the types of interactions that one can incorporate into a VLG and, in that light, the education literature is still weak in providing strategies to aid in the design of VLGs as well as the effectiveness of learning in students.

Hence, we conclude with future research which would propel virtual learning forward. The first step in research should be to identify the specific, various types of interactions (student-student or student-instructor) which VLGs afford and test their effectiveness in students' learning individually, in various contexts, in order to find out which are the most effective types of interactions in VLGs' learning and effectiveness. Next, to test equivalency as put forth by Anderson [26], substitutability of the various types of student-student and student-instructor interactions should be empirically tested: Can one type of interaction perfectly substitute the other without significantly affecting student's learning, satisfaction and retention? Experimentation is also needed, instead of simply using surveys and interviews with weak operationalisation and vague definitions of interactions. The lack of depth and rigour in this area of education research may not reflect so much of a lack of knowledge about the role interactivity plays in VLGs, as much as a reflection of researchers' failure to identify specific conditions and interactions related to these theories. In their haste find significant ways to operate VLGs, researchers have neglected the finer details of specific strategies which may lead to more effective outcomes. Altogether, the next steps in future research should be to plug the many holes in the virtual education literature by (1) identifying the specific, different types of interactions which may be beneficial in VLGs, (2) demarcating the contexts in which different modes of communication (synchronous or asynchronous) would be most effective, and to test for significant differences in learning outcomes when either form of communication is used, and (3) empirically testing the effects of the various aforementioned approaches and types of interactions singularly or in various permutations in various VLG settings.

\section{ACKNOWLEDGMENT}

J. C. Ng thanks Professor Joseph B. Walther for his guidance and insightful feedback on this paper.

\section{REFERENCES}

[1] S. Consortium. (2008). Staying the course: Online education in the United State. [Online]. Available: http://sloanconsortium.org/publications/survey/staying_course

[2] N. Carr, "The crisis in higher education," Technology Review, vol. 115, pp. 32-40, 2012

[3] A. Bischoff, "The elements of effective online teaching: Overcoming the barriers to success," The Online Teaching Guide: A Handbook of Attitudes, Strategies, and Techniques for the Virtual Classroom, pp. 57-72, 2000

[4] N. Croft, A. Dalton, and M. Grant, "Overcoming isolation in distance learning: Building a learning community through time and space,' Journal for Education in the Built Environment, vol. 5, pp. 27-64, 2010.

[5] S. Ludwig-Hardman and J. C. Dunlap, "Learner support services for online students: Scaffolding for success," The International Review of Research in Open and Distributed Learning, vol. 4, 2003.

[6] S. Carr, "As distance education comes of age, the challenge is keeping the students," Chronicle of higher education, vol. 46, pp. 39-41, 2000.

[7] J. Jun, "Understanding e-dropout?" International Journal on e-Learning, vol. 4, pp. 229-240, 2005.

[8] C. D. Rochester and F. Pradel, "Students' perceptions and satisfaction with a web-based human nutrition course," American Journal of Pharmaceutical Education, vol. 72, 2008.

[9] V. Tinto, A. Goodsell, and P. Russo, "Gaining a voice: The impact of collaborative learning on student experience in the first year of college," Syracuse University, 1993.

[10] A. Hron, F. W. Hesse, U. Cress, and C. Giovis, "Implicit and explicit dialogue structuring in virtual learning groups," British Journal of Educational Psychology, vol. 70, p. 53, 2000. 
[11] J.-H. Park and H. J. Choi, "Factors influencing adult learners' decision to drop out or persist in online learning," Journal of Educational Technology \& Society, vol. 12, pp. 207-217, 2009.

[12] A. P. Rovai and J. R. Downey, "Why some distance education programs fail while others succeed in a global environment," The Internet and Higher Education, vol. 13, pp. 141-147, 2010.

[13] S. F. Tello, "An analysis of student persistence in online education," International Journal of Information and Communication Technology Education, vol. 3, pp. 47-62, 2007.

[14] V. A. Thurmond, K. Wambach, H. R. Connors, and B. B. Frey, "Evaluation of student satisfaction: Determining the impact of a web-based environment by controlling for student characteristics," The American Journal of Distance Education, vol. 16, pp. 169-190, 2002.

[15] C.-H. Tu and M. McIsaac, "The relationship of social presence and interaction in online classes," The American Journal of Distance Education, vol. 16, pp. 131-150, 2002.

[16] P. A. Willging and S. D. Johnson, "Factors that influence students' decision to dropout of online courses," Journal of Asynchronous Learning Networks, vol. 13, pp. 115-127, 2009.

[17] S. Kiousis, "Interactivity: A concept explication," New Media \& Society, vol. 4, pp. 355-383, 2002.

[18] S. Rafaeli, "Interactivity: From new media to communication," Sage Annual Review of Communication Research: Advancing Communication Science, vol. 16, pp. 110-134, 1988.

[19] A. W. Chickering and Z. F. Gamson, "Seven principles for good practice in undergraduate education," AAHE Bulletin, vol. 3, p. 7, 1987.

[20] C. Daiute and B. Dalton, "Collaboration between children learning to write: Can novices be masters?" Cognition and Instruction, vol. 10, pp 281-333, 1993

[21] M. Scardamalia and C. Bereiter, "Text-based and knowledge based questioning by children," Cognition and Instruction, vol. 9, pp. 177-199, 1992.

[22] L. S. Vygotsky, Mind in Society: The Development of Higher Mental Process, Cambridge, MA: Harvard University Press, 1978.

[23] B. M. Hall, "Cultivating substantive peer interaction in online human service courses," Journal of Human Services, vol. 34, pp. 137-141, 2014.

[24] A. Sher, "Assessing the relationship of student-instructor and student-student interaction to student learning and satisfaction in web-based online learning environment," Journal of Interactive Online Learning, vol. 8, pp. 102-120, 2009.

[25] M. Allen, E. Mabry, M. Mattrey, J. Bourhis, S. Titsworth, and N. Burrell, "Evaluating the effectiveness of distance learning: A comparison using meta-analysis," Journal of Communication, vol. 54, pp. 402-420, 2004.

[26] T. Anderson, "Getting the mix right again: An updated and theoretical rationale for interaction," The International Review of Research in Open and Distributed Learning, vol. 4, 2003.

[27] R. M. Bernard et al., "A meta-analysis of three types of interaction treatments in distance education," Review of Educational Research, vol. 79, pp. 1243-1289, 2009.
[28] V. Tinto, "Dropout from higher education: A theoretical synthesis of recent research," Review of Educational Research, pp. 89-125, 1975.

[29] V. Tinto, Leaving College: Rethinking the Causes and Cures of Student Attrition, ERIC, 1987.

[30] A. P. Rovai, "In search of higher persistence rates in distance education online programs," The Internet and Higher Education, vol. 6, pp. 1-16, 2003.

[31] S. Liu, J. Gomez, B. Khan, and C.-J. Yen, "Toward a learner-oriented community college online course dropout framework," International Journal on e-Learning, vol. 6, pp. 519-542, 2007.

[32] L. V. Morris, C. Finnegan, and S.-S. Wu, "Tracking student behavior, persistence, and achievement in online courses," The Internet and Higher Education, vol. 8, pp. 221-231, 2005.

[33] R. Farzan, L. A. Dabbish, R. E. Kraut, and T. Postmes, "Increasing commitment to online communities by designing for social presence," in Proc. the ACM 2011 Conference on Computer Supported Cooperative Work, 2011, pp. 321-330.

[34] S. D. Reicher, R. Spears, and T. Postmes, "A social identity model of deindividuation phenomena," European Review of Social Psychology, vol. 6, pp. 161-198, 1995.

[35] T. Miyazoe and T. Anderson, "The interaction equivalency theorem," Journal of Interactive Online Learning, vol. 9, 2010.

[36] T. Anderson, "Towards a theory of online learning," Theory and Practice of Online Learning, vol. 2, pp. 15-44, 2008.

[37] C. Walker and E. Kelly, "Online instruction: Student satisfaction, kudos, and pet peeves," The Quarterly Review of Distance Education, vol. 8, pp. 309-319, 2007.

[38] J. Rhode, "Interaction equivalency in self-paced online learning environments: An exploration of learner preferences," The International Review of Research in Open and Distributed Learning, vol. 10, 2009.

[39] A. Espasa and J. Meneses, "Analysing feedback processes in an online teaching and learning environment: an exploratory study," Higher Education, vol. 59, pp. 277-292, 2010.

[40] K. H. Soon, K. Sook, C. Jung, and K. Im, "The effects of internet-based distance learning in nursing," Computers in Nursing, vol. 18, pp. $19-25,1999$.

[41] T. Berners-Lee, "Realising the full potential of the web," Technical Communication: Journal of the Society for Technical Communication vol. 46, pp. 79-82, 1999.

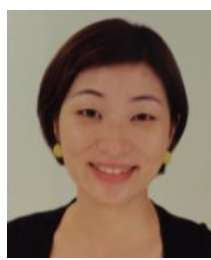

Jessica C. $\mathbf{~ N g}$ is a post-graduate student at the Wee Kim Wee School of Communication and Information, Nanyang Technological University, Singapore. 